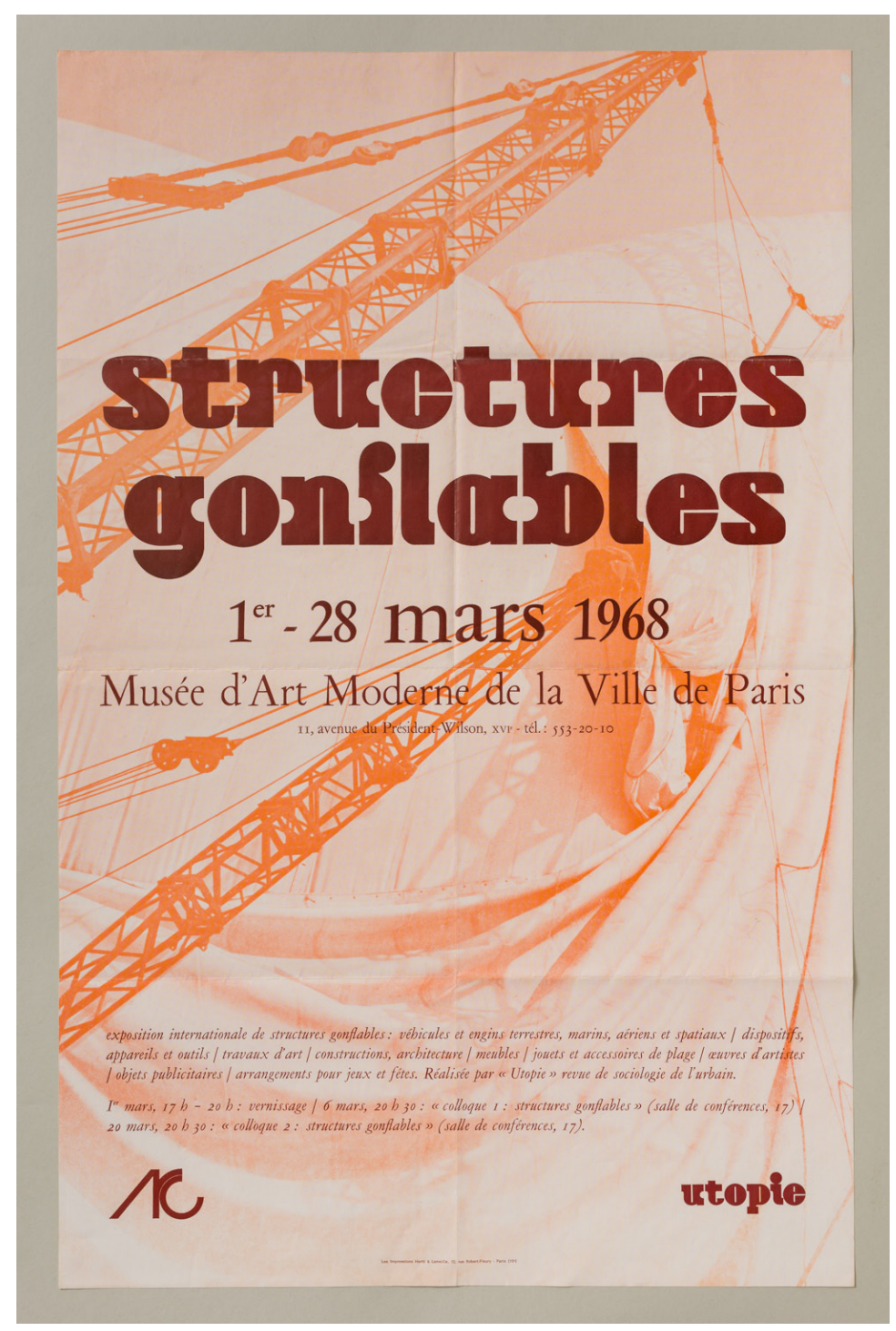




\section{Apuntes sobre el paso de medio siglo (y algunas exposiciones) Patricio Mardones}

La exposición "Structures Gonflables" presentada por el grupo francés Utopie en el inquieto París de fines de los años sesenta instala la posibilidad de otra relación entre la disciplina arquitectónica y el espacio del museo, algo lejana a la planteada por Rossi en la conferencia de 1966 "Architettura per i musei". Antes que púlpito desde donde se señalan caminos, el museo es una arena de encuentros y cruces, en el que la arquitectura puede redefinirse y desplazar sus bordes. Es en estos años de redefiniciones cuando se consolidan modelos como el DIY y se amplía la noción de producción arquitectónica y proyecto desde el edificio a medios como el film, el dibujo y el fotomontaje.

\section{PALABRAS CLAVE}

Arquitectura radical, 1968, Utopie, Superstudio, Matta-Clark

KEYWORDS

Radical Architecture, 1968, Utopie, Superstudio, Matta-Clark

Entre el primero y el treinta de marzo de 1968, el Musée d'Art Moderne de la Ville de Paris, a través de su nueva división ARC (Animation, Recherche, Confrontation) presentó la exposición Structures Gonflables. A pocas semanas del estallido de los movimientos sociales que convirtieron las calles de París en sitio de debate y enfrentamientos, el colectivo multidisciplinar Utopie -integrado por los arquitectos Jean Aubert, Jean-Paul Jungmann y Paul Stinco, junto a Isabelle Auricoste, Catherine Cot, René Loureau y los sociólogos Jean Baudrillard y Hubert Tonka- monta en este lugar y por encargo de Pierre Gaudibert una exhibición que intentaba, según declaraba su afiche, constituirse una revisión exhaustiva sobre "el arte, la tecnología y el imaginario de los inflables en todos los ámbitos, incluyendo vehículos terrestres, marítimos, aéreos y
Patricio Mardones Hiche

(Antofagasta, 1973) Arquitecto por la Pontificia Universidad Católica de Chile (1999); durante 1993 cursó estudios de Arte en la misma Universidad. Desde el año 2000 ha combinado práctica profesional, docencia y labores editoriales. A partir de 2007 ha colaborado con medios y revistas como Icon (Inglaterra), Mark (Holanda), Dwell (EE.UU), 2G (España), The Plan (Italia), AU (Brasil), Casabella (Italia), Azure (Canadá), Oris (Croacia); T magazine/NYTimes (EE.UU.). Ha participado como curador en exposiciones de arquitectura en Chile, Suiza y los Estados Unidos. Entre 2011 and 2015 fue director de Ediciones ARQ en la Escuela de Arquitectura de la Pontificia Universidad Católica de Chile. Es coautor de la segunda etapa de la Biblioteca del Centro de Documentación SLGM de la Escuela de Arquitectura de la Pontificia Universidad Católica de Chile, (asociado a Cecilia Puga, 2007) y de la nueva Cripta y presbiterio de la Catedral Metropolitana de Santiago (asociado a Rodrigo Pérez de Arce y Sebastián Bianchi, 2006). Sus últimos proyectos incluyen la Infraestructura de uso público del Parque Nacional Queulat en Aysén (1er premio, concurso 2016) y el Terminal de Cruceros del puerto de Punta Arenas (1er premio, concurso 2017), en ambos asociado a Cecilia Puga y Paula Velasco. En 2007 fue profesor visitante en The University of Texas at Austin. Actualmente colabora en el estudio de Smiljan Radic, es profesor en la Universidad Andrés Bello y en la Pontificia Universidad Católica de Chile y es miembro del directorio de la Fundación de Arquitectura Frágil en Santiago.

Fig. 01

Cartel de la la exposición Structures Gonflables, Musée d'Art Moderne de la Ville de Paris, 1-30/03/1968. 
espaciales, obras de arte, construcciones, arquitectura, mobiliario, juguetes, dispositivos publicitarios y recreativos". Buena parte de la copiosa selección de objetos que constituía la exposición provenía de catálogos; el objetivo curatorial era revelar posibles transferencias tecnológicas desde diferentes industrias -entre ellas la bélica, particularmente aquella desarrollada por EE.UU.- hacia la arquitectura. Junto a estos productos, era posible revisar dibujos y fotografías de modelos de los proyectos de fin de carrera elaborados un año antes por los jóvenes Aubert, Jungmann y Stinco' en el taller dirigido por Edouard Albert en l'Ecole nationale supérieure des Beaux-Arts de París. Se trataba, respectivamente, de "Un podium itinérant pour 5.000 spectateurs", "Dyodon, habitation pneumatique expérimentale" y "Un hall itinérant d'exposition d'objets de la vie quotidienne": tres propuestas realizadas en torno a la pesquisa de grandes estructuras desmontables y el uso de membranas plásticas ${ }^{2}$, que suponían la aparición de una arquitectura móvil y ligera para un mundo móvil y ligero, en completa oposición a la inercia física y social de las arquitecturas de piedra y concreto tan caras a la tradición beauxartiana, e igualmente lejanas al pensamiento revolucionario más radicalizado de los jóvenes maoístas y trotskistas que, por esos días, agitaban los campus universitarios europeos. En el recuerdo del propio Aubert ${ }^{3}$, las facciones más duras del movimiento estudiantil despreciaban a los objetos (incluso a los inflables) porque encarnaban una manifestación productiva vinculada al capital y a la lucha de clases.

Parte de la última horneada de proyectos desarrollados en l'Ecole nationale supérieure des Beaux-Arts antes de la completa reestructuración que impulsaron las demandas estudiantiles del año 68, los proyectos de titulación de los tres jóvenes arquitectos de Utopie se presentaron al lado de desarrollos técnicos como zeppelines y balsas de rescate manufacturadas por Zodiac, desmarcando la arquitectura del ámbito aburguesado y ciertamente formal al que se le asociaba, pero alimentando sus conexiones con el mundo material. Los dibujos y modelos de estos proyectos adquieren la categoría de arquitecturas para museo en tanto se presentan dentro de una institución que parece promover la discusión pública, pero se sitúan relativamente distantes de la definición de pieza museística a la que Rossi se refiere recordando a Cézanne" la forma más elevada de la arquitectura, autónoma y abierta, destinada a ser desarrollada por técnicos para su posterior adaptación a alguna posible función o implementación, para su "puesta en realidad". Por el contrario, las obras -dibujos y modelos- de A.J.S., presentadas en el Musée d'Art Moderne de la Ville de Paris, están explícitamente vinculadas a ciertos desarrollos tecnológicos, que a su vez están situados en un contexto social y político muy específico. Su nivel de autonomía del contexto está atenuado por un compromiso cultural, que contamina la pureza museística a la que pareciera aspirar Rossi. $Y$ aunque algunas de estas piezas son efectivamente planimetrías, se alejan igualmente de la noción propuesta por Jean Nicholas Louis Durand, quien señaló al dibujo arquitectónico como medio para describir un objeto que está en otro dominio, como anticipación de otra cosa (probablemente, del edificio). Vista así, la aproximación de Durand colabora en acentuar la dicotomía enunciada por Rossi, apartando una arquitectura para el museo, pura, autónoma y hasta cierto punto ensimismada, de otra mundana, informada por demandas contextuales, presupuestos o consideraciones técnicas y que derivaría de la primera. 


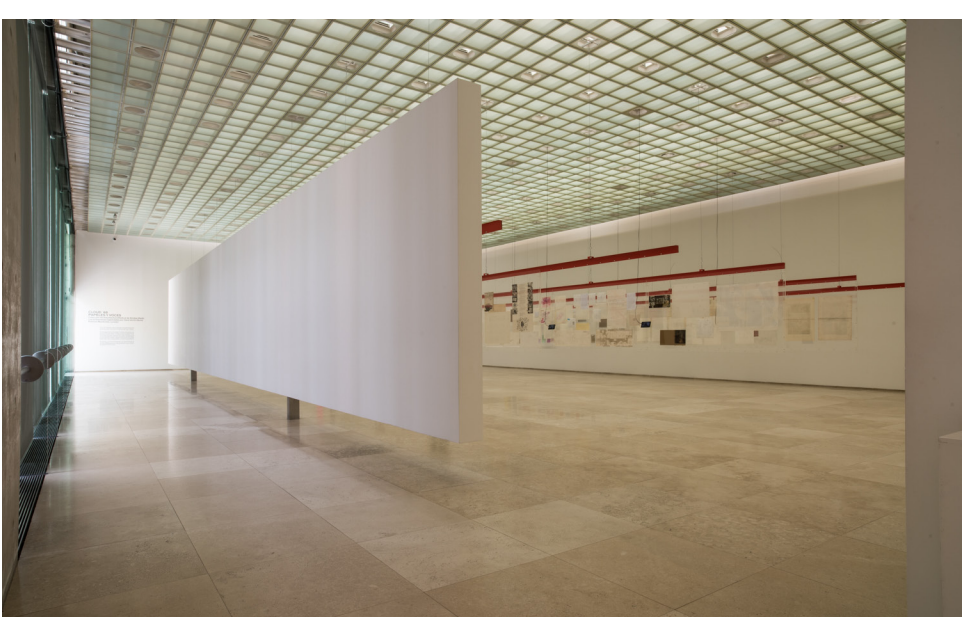

02

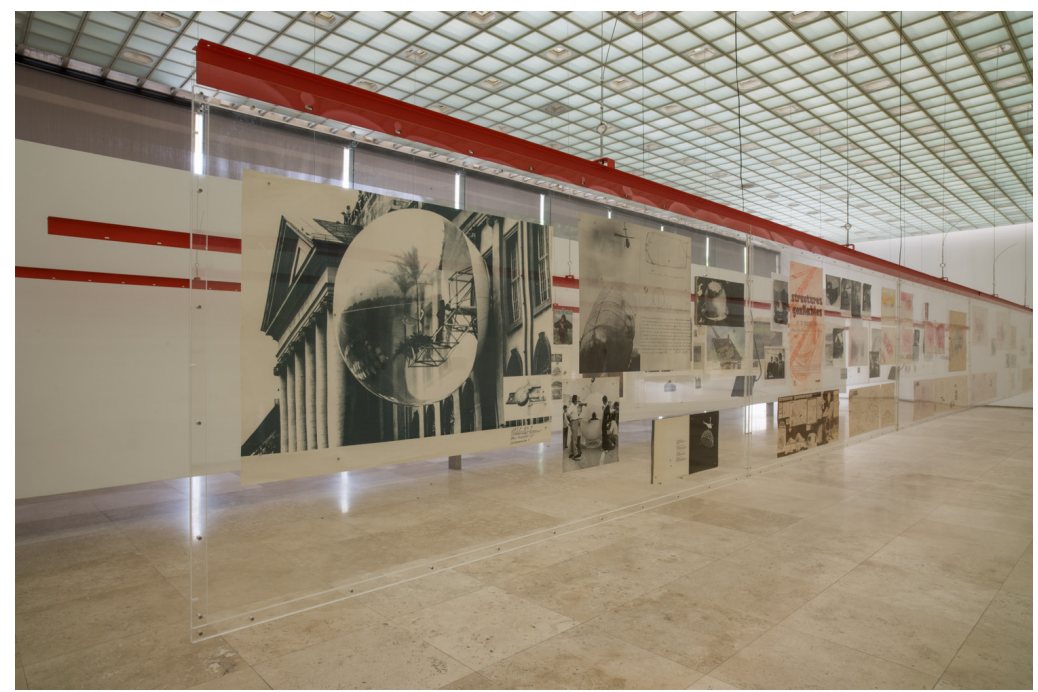

03

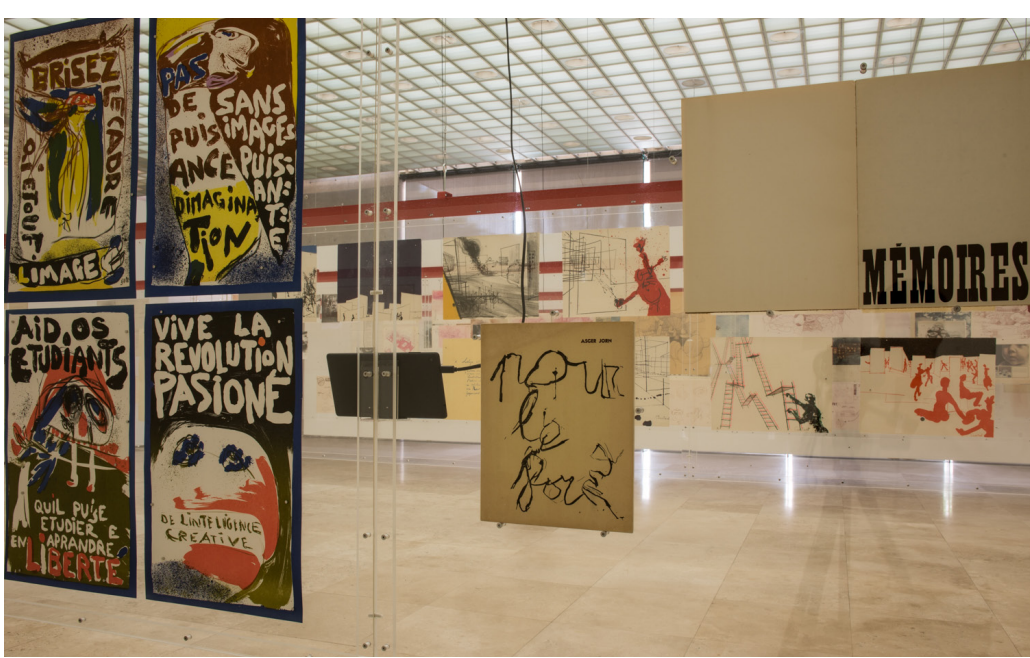

04
Fig. 02

Cloud '68-Papeles y Voces es el proyecto de una exposición desarrollada entre 2016 y 2018 por la Fundación de Arquitectura Frágil, con el apoyo de gta Exhibitions de ETH Zurich, el Área de Arquitectura del Ministerio de las Culturas, las Artes y el Patrimonio del Gobierno de Chile y Hunter Douglas Chile. Trata sobre la arquitectura que una serie de movimientos radicales europeos produjeron en la segunda mitad del siglo $X X$, y vincula parte de dos colecciones que se entrelazan en esos tiempos.

\section{Fig. $\mathrm{O3}$}

La primera pertenece al arquitecto chileno Smiljan Radic; de ella proviene una selección de 173 piezas de papel que incluye tanto efímera como litografías, dibujos y grabados originales. La segunda es un conjunto de 13 videos realizados por el crítico y curador suizo Hans Ulrich Obrist, quien en diferentes momentos entrevistó a los protagonistas de dicha arquitectura.

\section{Fig. 04}

El nombre del proyecto, propuesto por Hans Ulrich Obrist, hace alusión a la arquitectura y al pensamiento de los movimientos radicales que surgieron en Europa entre los años cincuenta y setenta, que orbitaron de manera borrosa en torno a la revolución de mayo de 1968 en París. Literalmente, la producción que dejaron estos colectivos quedó en su mayoría en el papel; lejos de convertirse en una condición peyorativa, este hecho terminó siendo una ventaja que facilitó su difusión, y estimuló el desborde de los límites disciplinares al promover cruces con artistas, poetas, diseñadores $e$ ingenieros. Esa es la coordenada para situar este conjunto de impresos que incluye manifiestos, postales, posters, mapas y dibujos, y que es el espejo de las voces de estos autores. 
Fig. 05

El material se expuso entre marzo y mayo de 2018 en la Galería ArCHena del Departamento de Arquitectura de ETH Zurich, y entre octubre y noviembre en la Galería Patricia Ready en Santiago. 33 vitrinas de acrílico de $240 \times 120 \mathrm{cms}$, se agruparon en 5 frisos paralelos, cada uno colgado de una viga metálica coloreada de $\mathbf{2 0} \mathrm{m}$ de largo suspendida desde del cielo de la sala, dejando un espacio de 2,40 m de ancho entre una y otra.

Fig. 06

Estas bandas transparentes fueron el soporte de las obras y voces Constant Nieuwenhuys, Guy Debord, Asger Jorn, Haus-Rucker-Co, Archigram, Utopie, y Superstudio, entre otros; el montaje intentaba emular las lecturas múltiples y no lineales que permitían los paneles del Atlas Mnemosyne de Aby Warburg, al tiempo que construía al interior de la sala una imagen coral, polifónica y a ratos contradictoria. La sensación de una nube de imágenes y murmullos, producidos hace cincuenta años.

El proyecto se propuso redirigir la mirada hacia esta "segunda fila" de la historia de la arquitectura del siglo $\mathrm{XX}$, fuertemente dominada por el movimiento moderno. Cloud '68-Papeles y Voces se concentró en un puñado de autores que de alguna forma trabajaron al margen de los discursos dominantes, casi fuera del campo de la arquitectura. No fueron ellos quienes construyeron las ciudades y edificios del siglo pasado; por el contrario, trabajaron en los bordes de la disciplina para producir manifiestos, dibujos e imágenes que descartaban cualquier tipo de negociación, y que se materializaron directamente con medios relativamente modestos. Esa cualidad inmediata, poco usual en la arquitectura, es una condición que la exposición intentó poner en valor.

Fig. 07

La Fundación de Arquitectura Frágil, con residencia en Santiago, se constituyó legalmente en enero de 2018 y su objetivo promover el estudio y difusión de la Arquitectura Experimental o de Realidad Improbable-aquella donde se desdibujan los límites de la disciplina- a través de proyectos de investigación y difusión en Chile. Aquí, el acceso a la arquitectura en todas sus representaciones continúa siendo una ventaja accesible sólo para unos pocos arquitectos. Chile sigue estando lejos.

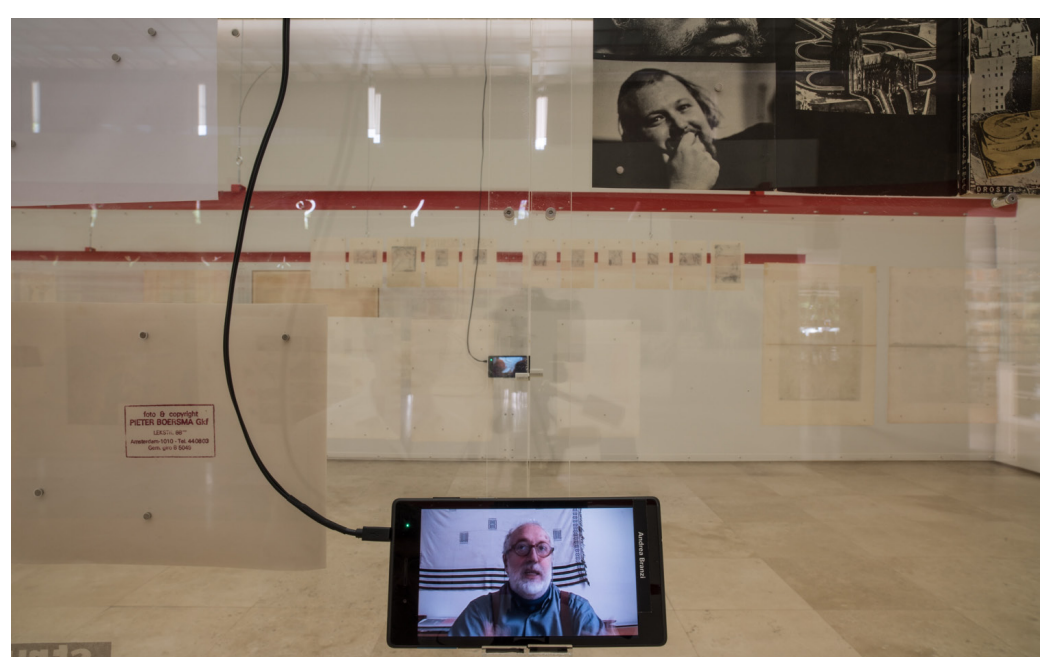

05

La arquitectura dentro de Structures Gonflables parece bajo este prisma como una entidad contradictoria, impura y gris, quizá porque no encaja en la linealidad temporal que ve el dibujo como mera proyección de una realidad que se verifica a posteriori. Y justamente por este rasgo es que ella puede emparentarse con relativa naturalidad con la producción de otros autores de la segunda mitad del s. XX, agrupados posteriormente bajo el rótulo de arquitectura radical que, inicialmente, había sido acuñado por Alessandro Mendini para referirse a algunos colectivos de jóvenes arquitectos y diseñadores surgidos en Florencia ${ }^{5}$. En el mismo (y necesariamente amplio) espectro que incluye a los italianos de Superstudio, 9999, Archizoom y UFo, pueden ubicarse algunos metabolistas japoneses, Constant Nieuwenhuys, Archigram, Wolf Vostell o Haus Rucker; todos ellos produjeron obras que, por su condición material, escala o naturaleza, también terminaron por constituirse en piezas de colección museística, aunque con una salvedad: su realidad como objeto arquitectónico es última y definitiva. Se representan a sí mismas, y no suponen un estado ulterior de desarrollo o realización; más bien, aparecen como entidades conclusas. La liberadora apuesta por el proyecto (y sus instrumentos) como producto arquitectónico final se expande alrededor de la segunda mitad de los años sesenta, y en torno a ella surgen nuevos métodos de enseñanza de la arquitectura y el interés de diversas personalidades o instituciones en cautelar y cultivar este punto de vista ${ }^{6}$. El período de Alvin Boyarsky en The Architectural Association de Londres (1971-1990) es un caso ejemplar de estas prácticas, y tuvo una particular consonancia con la producción editorial y visual que el grupo Archigram, Hans Hollein y Cedric Price habían desarrollado a fines de los años sesenta. Otro ejemplo es el modelo educativo que John Hejduk impulsó en The Cooper Union en Nueva York a partir de 1975, institución que amparó las experiencias pedagógicas (y los densos dibujos) de Lebbeus Woods.

Las revisiones sociales surgidas en la post guerra y la ambiciosa urgencia por comunicar y comprometer a audiencias cada vez más numerosas alimentaron muchos de los impulsos creativos de llamada arquitectura radical del hemisferio norte. La mayor parte del tiempo trabajaron instalados en los márgenes de la disciplina, con limi- 
tado acceso a encargos y por lo mismo frecuentemente exentos de las negociaciones propias de la práctica profesional convencional, libertad que simultáneamente restringió los recursos con los que contaron para producir su obra. El afecto de estos grupos por la autoconstrucción, la reproducción por la vía del "hágalo Ud. mismo"7 las membranas plásticas, los inflables y las piezas gráficas (posters, fanzines y postales, por ejemplo) puede explicarse parcialmente por este factor con implicancias tan mundanas como ideológicas: éste era el tipo de producción que ellos podían costear con recursos propios, desmarcada de los sistemas de poder y acumulación de capital que frecuentemente constituyen el soporte de la práctica arquitectónica y los cuales ellos, precisamente, se proponen evadir. Para Aubert, en eso consiste la impracticable práctica de la arquitectura, aquella que produce objetos a la vez que intenta criticar los sistemas financieros y políticos que gobiernan su producción.

Es justamente la aversión a esta relación entre arquitectura y las formas tradicionales de poder la que alimenta el desarrollo de medios que contribuyeran a la transferencia de ideas y conocimientos a las masas. Al tiempo que producían manifiestos que condensaban postulados e ideologías que no se ofrecían al público necesariamente con facilidad -y que terminaron por circular en órbitas intelectuales más bien confinadas- los movimientos de la llamada arquitectura radical tenían

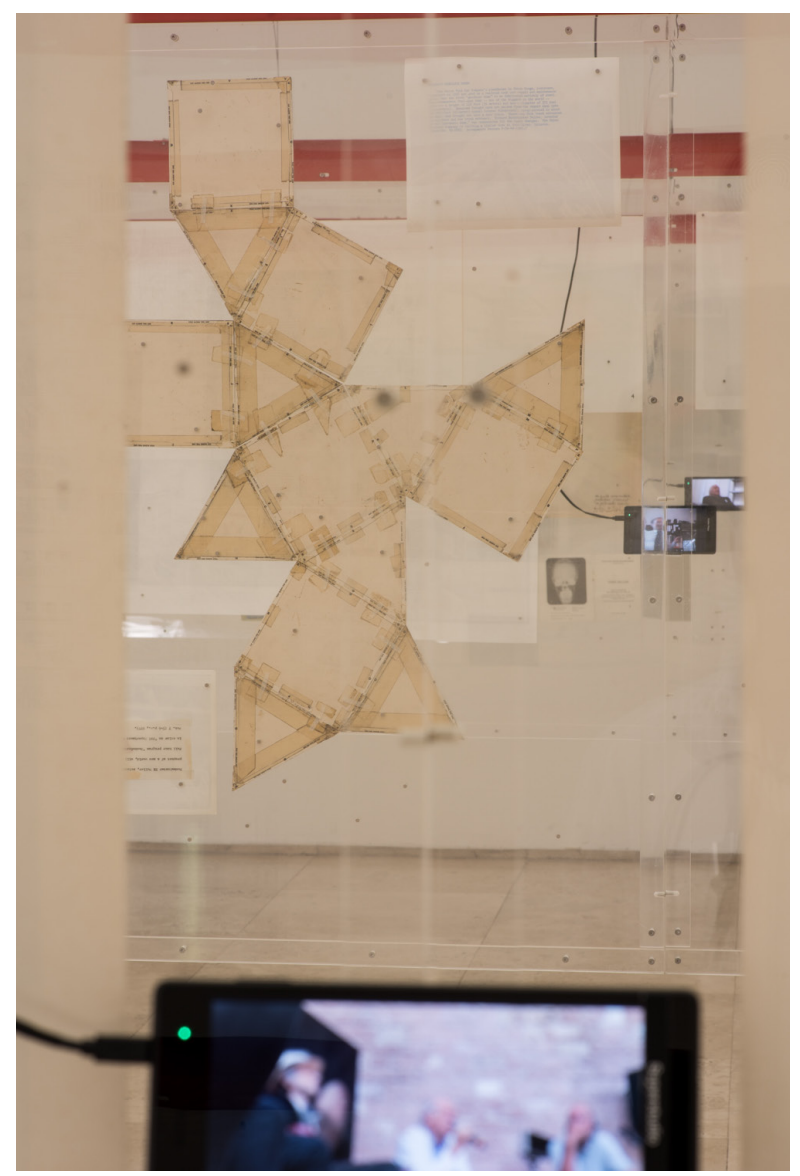

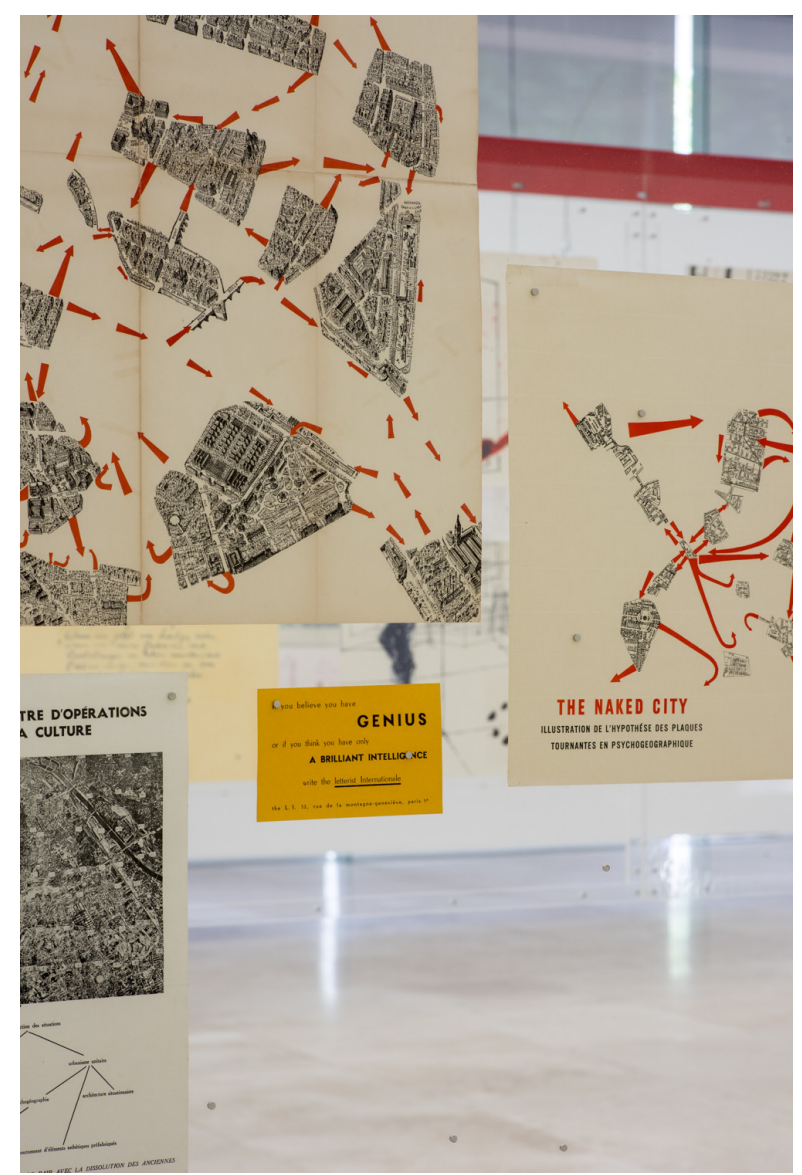

07 
una clara conciencia del valor de la comunicación visual como herramienta efectiva para captar atención y adeptos. El extensivo uso que los arquitectos radicales hacen del dibujo y la proliferación de prácticas como el collage o el détournement aplicadas sobre películas, cómics y piezas publicitarias muestran el aprecio de estas generaciones por las imágenes, inclinación que ha tenido un impacto significativo en la cultura y el discurso arquitectónico contemporáneos. El vehículo más eficaz para la comunicación de ideas sería un objeto o una imagen, en sintonía con la frase acuñada por Walter Benjamin en El libro de los pasajes: "No tengo nada que decir, sólo que mostrar". El traslado desde un discurso textual a uno visual y la efusiva producción de piezas gráficas y pequeños objetos como principal producción arquitectónica facilitó la circulación

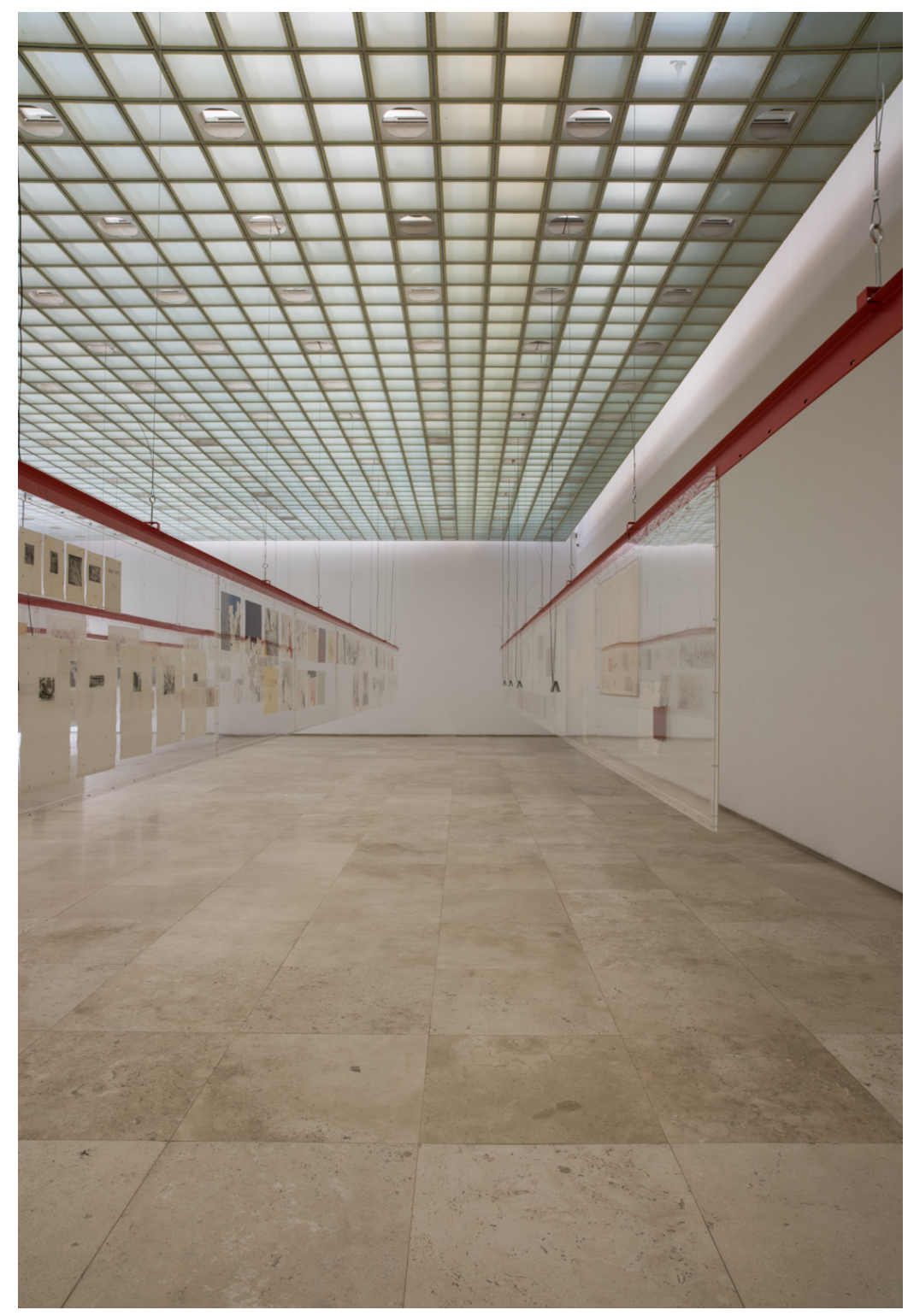


de las ideas de la contracultura radical en galerías, museos y medios de circulación masiva, y hay al menos dos casos extremos de esta atención a la capacidad comunicativa de la producción arquitectónica que parece importante recordar. Uno de ellos es el trabajo de Matta Clark, el que justamente plantea una serie de dificultades de orden práctico a la hora de exponerse en el ambiente de un museo; su autor decía, sobre el valor e interés de sus intervenciones en estructuras abandonadas: "el factor determinante es el grado en que mi intervención puede transformar la estructura en acto de comunicación". El segundo ejemplo de esta traslación lo constituye la entrada de la arquitectura al mundo del cine (y lateralmente, al de la publicidad) a través de los cortometrajes que Superstudio habían planeado para cada uno de los cinco Actos Fundamentales, y de

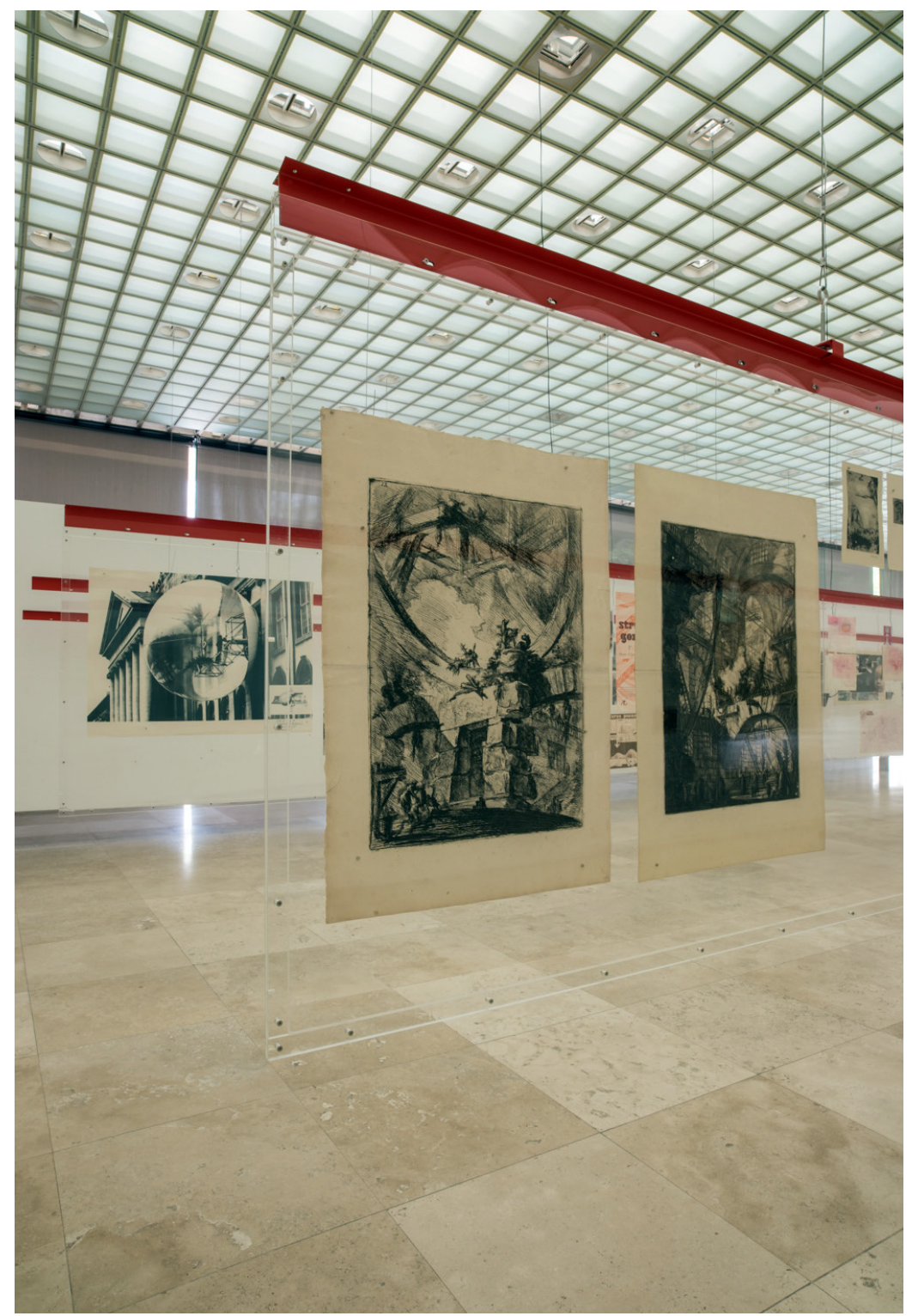

Fig. 08

Al promover una importación de ideas, la Fundación traería nuevos recursos de debate, $o$ al menos, una visualidad que con el sólo hecho de existir implicará cualidades educativas que serán especialmente estimulantes para los arquitectos jóvenes chilenos. Con estos objetivos se conformó un directorio nacional compuesto por Tomás Müller Benoit, Alberto Sato, Enrique Walker, Patricio Mardones y Smiljan Radic, y una necesaria comisión de asesores externos compuesta por Julia Peyton-Jones, Erwin Viray, Moisés Puente y Giorgio Mastinu.

Fig. 09

Entre 2017 y 2018 se han realizado dos actividades de las cuales la Fundación ha sido patrocinante. Primero, la exposición 'Other people have dogs' realizada juntamente con la Fundació Enric Miralles de Barcelona en la galería D21 en Santiago. En segundo lugar, la exposición 'Cloud 68, Papeles y Voces', que se presentó en Zurich y Santiago. En 2021 se presentará un tercer proyecto de exposición, actualmente en preparación. 
* Patricio Mardones dirigió el proyecto curatorial de CLOUD'68 Papeles y Voces, sobre la base de la catalogación de la colección de Smiljan Radic en la que colaboraron Irene Abujatum, Roberta Garieri y Gonzalo Puga. Caterina Miralles y Guillermo Zilleruelo colaboraron en Santiago durante el desarrollo del proyecto curatorial de CLOUD'68 Papeles y Voces. Alejandro Lüer, Fernanda Cabezas y Andrés Moris colaboraron en Santiago durante el desarrollo del proyecto del montaje de CLOUD'68 Papeles y Voces. Niels Olsen, Fredi Fischli, Daniel Sommer, Valentina Ehnimb y Sabine Sarwa, del equipo de gta exhibitions, apoyaron en Zurich la materialización del proyecto. Max Shackleton desde Londres compiló y organizó los registros de video y grabaciones del archivo de entrevistas de Hans Ulrich Obrist. Teo Schifferli en Zurich realizó el proyecto gráfico para la identidad de CLOUD'68 Papeles y Voces. Gonzalo Puga realizó el registro fotográfico de CLOUD'68 Papeles y Voces en la Galería Patricia Ready en Santiago. El autor agradece a Christian Kerez y Philip Ursprung, del departamento de Arquitectura de ETH Zürich; Cristóbal Molina, del Ministerio de las Artes, la Cultura y el patrimonio del Gobierno de Chile; Patricio Mardones Precht, Andrea Monsalve y Erwin Weisse, de Hunter Douglas Chile, apoyaron la realización del proyecto en Zurich y Santiago. los que se realizaron únicamente dos; sin embargo, los story-boards del proyecto terminaron por constituirse en sí mismos como obra. La misma suerte corrió la película no realizada para el Monumento Continuo, cuyo story-board fue publicado en 1971 por la propia revista Casabella y de donde provienen múltiples imágenes que fueron desarrolladas más tarde como collages $y$ fotomontajes de diverso formato. Estas piezas visuales adelantan en varias décadas recursos y procedimientos hoy corrientes en la producción y reproducción del proyecto de arquitectura, en el tránsito desde la aplicación de aerógrafo sobre recortes de papel y fotocopias hacia el diseño digital de layers y pixeles.

En el panorama actual, la influencia de los proyectos radicales de los sesenta y setenta y la ampliación en torno a la idea de producción arquitectónica es significativa. De hecho, hay continuidades innegables en un proceso de crítica, contradicciones y revisiones que no parece haber terminado aún, y donde las reflexiones de Rossi sobre la teoría del diseño arquitectónico expuestas en Architettura per i musei resuenan con especial energía, amplificada si por descuido o provocación reemplazamos la palabra original museo por escuela.

Cruzadas en la transferencia de ideas y conocimientos a las masas, y con una conciencia creciente de su poder y responsabilidad políticos, ambas instituciones y sus sistemas de validación (que incluyen áreas compartidas como bienales y trienales) mantienen los debates sobre la crisis de una profesión que intenta desactivar su debilitación, en un contexto cultural cada vez más dominado por las ciencias exactas. No está de más recordar la reacción de Gordon Matta-Clark, quizá el arquitecto más museístico de todos, quien ante la pregunta de Donald Wall por su alejamiento de la práctica profesional en el contexto de la dicotomía entre arquitectos profesionales y teóricos responde con una claridad al borde de la impertinencia'. Inquiere Wall: ¿Le inquieta ocupar una posición ideológica diametralmente opuesta a la del arquitecto practicante, y a todo lo que significa esa profesión en cuanto a resolver los problemas de la humanidad? La réplica de Matta Clark no se deja esperar, y diluye abruptamente la brecha entre unos y otros: No creo que la mayoría de los practicantes esté resolviendo nada aparte de cómo ganarse la vida. La arquitectura es un gran negocio. Es una actividad enormemente costosa, y por lo tanto viene equipada, como el gobierno, con todo su arsenal de propaganda. RA 
Notas

01. A.J.S.- Aérolande fue el acrónimo que los tres arquitectos escogieron tomando las iniciales de sus apellidos, para presentarse públicamente como una oficina de arquitectos. Más tarde, ella encontraría en la producción de piezas de mobiliario inflable una veta para su realización profesional y una fuente de sustento económico.

02. El proyecto de Jean Aubert era un domo con una especie de estructura nervada inflable, bajo cuyo manto se disponían graderías dispuestas en arco y que asumía la vocación de un gran pabellón desmontable; el proyecto de Jungmann proponía una estructura inflable de varios niveles, que alojaba espacios de residencia, susceptible de instalarse en diferentes contextos geográficos $y$, seguramente, influenciada por la imaginería de las colonias extra-planetarias asociadas a la carrera espacial. Finalmente, el proyecto de Stinco proponía un gran manto que, asociado a grandes esferas inflables y a los mismos camiones de carga que permitían su traslado, cubría una enorme superficie como hall de exposiciones.

03. Según la entrevista que Craig Buckley hizo a Aubert en París en 2007, y que fue publicada en la reedición de 2010 realizada por Actar de Clip, Stamp, Fold: The Radical Architecture of Little Magazines, 196X to $197 X$ de Beatriz Colomina (ed.).

04. En el ensayo de 1960 Architettura per imusei, que desarrolla posibles relaciones entre la teoría y el diseño arquitectónico, Rossi escribe: "E ancora potremmo avere per divisa la celebre frase di Cézanne, "io dipingo solo per i musei". Con questa frase Cézanne, in modo chiarissimo, dichiara la necessità di una pittura che prosegue un suo sviluppo logico rigoroso e che si pone all'interno della logica della pittura che, appunto, viene verificata nei musei". Y declara en el párrafo final: "'L'architettura, nata dalla necessità, è ora autonoma; nella sua forma più elevata essa crea dei pezzi da Museo a cui si rifaranno i tecnici per trasformarli e adattarli alle molteplici funzioni e esigenze a cui devono essere applicati. Cosi dobbiamo educarci sull'analisi dei caratteri costitutivi di un progetto; ed è questo che deve proporsi un corso di teoria della progettazione".

05. La frase "radical design", en inglés, aparece en la portada de la revista Casabella n. 367, editada por el propio Mendini y publicada en Milán en el verano de 1972. Montada sobre el pecho de la figura de un gorila (tomada de una postal que retrata la muestra de mamíferos africanos del Museo Americano de Historia Natural de Nueva York) el número presenta extensamente el proyecto de los cinco actos fundamentales de Superstudio a pocas semanas de inaugurada en el MoMA la exposición Italy: the new domestic landscape, curada por Emilio Ambasz. Para críticos como Peter Lang, la ambiciosa exposición de los italianos en Nueva York supone el triunfo de la apropiación de sus ideas por parte del sistema que ellos mismos intentan repeler.

06. Radical Pedagogies, la investigación colaborativa de un grupo de doctorandos de la Universidad de Princeton dirigida por el equipo de Beatriz Colomina, Britt Eversole, Ignacio G. Galán, Evangelos Kotsioris, Anna-Maria Meister y Federica Vannucchi, ha contribuido a levantar una serie de experiencias sobre la enseñanza de la arquitectura que se desarrollaron a partir del término de la Segunda Guerra Mundial, en la búsqueda de modelos alternativos que era parte del ánimo de las vanguardias radicales. Muchas de ellas comparten el interés por alejarse de la inercia y formalidad que caracterizó la pedagogía arquitectónica en la primera mitad del siglo XX.

07. Ejemplos de esta corriente, que impulsó iniciativas de gran diversidad, son las publicaciones del pequeño manual para construcción de mobiliario en madera Proposta per unáautoprogettazione de Enzo Mari en 1974 y de Inflatocookbook de Ant Farm (Chip Lord, Curtis Schreier, Andy Shapiro, Hudson Marquez, Doug Hurr y Doug Michels), auto-editado por sus autores en California en 1970-71 y que incluía patronajes para el ensamble casero de grandes burbujas inflables. Ambos proyectos son, en rigor, compilaciones producto de una investigación personal de los autores.

08. Gordon Matta-Clark entrevistado por Donald Wall en Arts Magazine, mayo de 1976.

09. Ibid.

\section{Referencias bibliográficas}

- AUBERT, Jean; DIETRICH-SAINSAULIEU, Gérard; JUNGMANN, Jean; STINCO, Paul Antoine (Utopie); AURICOSTE, Isabelle; GAIGNEBET, Claude; GAIGNEBET, Léon; TONKA; HUBERT. Structures Gonflables. Utopie-Revue de sociologie de l'urbain; Musée d'Art Moderne de la ville de Paris, París, 1968.

- COLOMINA, Beatriz; BUCKLEY, Craig eds. Clip/Stamp/Fold: The Radical Architecture of Little Magazines, 196X to 197X. Actar \& Media and Modernity Program, Princeton University, Barcelona, Basilea y Nueva York, 2010.

- DESSAUCE, Marc (ed.). The Inflatable Moment: Pneumatics and Protest in '68. Princeton Architectural Press y The Architectural League of New York, Nueva York, 1999).

- MOURE, Gloria (ed.). Gordon Matta-Clark: Obras y escritos. Polígrafa, Museo Nacional Centro de Arte Reina Sofía (MNCARS), Barcelona y Madrid, 2006.

- NATALINI, Adolfo; TORALDO DI FRANCIA, Cristiano; MAGRIS, Alessandro; MAGRIS, Roberto; FRASSINELLI, Piero (Superstudio). "Vita educazione cerimonia amore morte. Cinque storie del Superstudio" (Vita). En MENDINI, Alessandro. Casabella n. 367, Editrice Casabella, Milán, 1972.

- ROSSI, Aldo. "Architettura per i musei" (1966). En AA. VV., Teoria della progettazione architettonica, Dedalo libri, Bari, 1968.

- VIOLEAU, Jean-Louis, Les Architectes et Mai 68. Éditions Recherches, París, 2005.
RA. Revista de Arquitectura Núm. 21 - 2019

P. 22-31 